\title{
Avaliação institucional e formação docente como práticas dialógicas na Educação Infantil
}

\section{Institutional evaluation and teacher education as dialogical practices in Early Childhood Education}

\author{
Maria Nilceia de Andrade Vieira* \\ Valdete Côco*
}

\begin{abstract}
RESUMO
Este artigo integra a pesquisa que focaliza a avaliação institucional na Educação Infantil no contexto de um município brasileiro. Nele se analisa os movimentos formativos docentes decorrentes dessa ação avaliativa. Com ancoragem em referenciais teórico-metodológicos bakhtinianos, a referida pesquisa caracteriza-se pela abordagem qualitativa e de caráter exploratório, com procedimentos de análise documental e realização de entrevistas semiestruturadas. No escopo deste texto, focalizam-se, especialmente, os enunciados expressos nas entrevistas realizadas com onze docentes. A análise dos dados evidencia a configuração de um evento marcado pela multiplicidade de vozes que compõem o debate sobre a qualidade da Educação Infantil ofertada, em articulação com a defesa do direito das crianças à educação e do reconhecimento e valorização dos docentes. Conclui-se que a avaliação institucional encerra grande potencial formativo para os envolvidos, uma vez que pode instar movimentos dialógicos situados numa pauta em disputa nas políticas públicas atuais.
\end{abstract}

Palavras-chave: Educação Infantil. Avaliação institucional. Formação docente.

* Universidade Federal do Espírito Santo. Programa de Pós-Graduação em Educação. Vitória, Espírito Santo, Brasil. E-mail: nilceia_vilavelha@hotmail.com. http://orcid.org/0000-0001-77236490. E-mail: valdetecoco@hotmail.com. https://orcid.org/0000-0002-5027-1306. 


\begin{abstract}
This article, based on research focused on institutional evaluation within Early Childhood Education in the context of a Brazilian municipality, analyzes the educational formative movements resulting from this evaluative action. Supported by Bakhtinian theoretical-methodological references, this research is characterized by its qualitative and exploratory approach, with documental analysis procedures and semi-structured interviews. In the scope of this text, we focus especially on the statements expressed in interviews with eleven teachers. The data analysis shows the configuration of an event marked by the multiplicity of voices that make up the debate on the quality of Early Childhood Education as it is offered, in articulation with the defense of children's right to education and the recognition and appreciation of teachers. We conclude that institutional evaluation has great formative potential for those involved, since it can urge dialogical movements situated in a disputed agenda within current public policies.
\end{abstract}

Keywords: Early Childhood Education. Institutional evaluation. Teacher education.

\title{
Introdução
}

Em atinência à agenda político-acadêmica emergente, sobretudo na atenção à possibilidade de discutir os fluxos hegemônicos e contra hegemônicos que incidem no trabalho educativo, tomamos como pauta a avaliação, direcionando o foco para a etapa da Educação Infantil. Articulada à influência de organismos internacionais e de lógicas de mercado, que vêm determinando diferentes pautas no campo da educação, a avaliação adquire relevância estratégica nas políticas públicas brasileiras. Tal relevância pode ser evidenciada, dentre outros ordenamentos legais, no Plano Nacional de Educação (PNE) (BRASIL, 2014). Nesse documento, embora nenhuma das 20 metas focalize diretamente a avaliação, $14(70 \%)$ delas apresentam no mínimo uma estratégia com previsão de ação avaliativa (CÔCO et al., 2015).

Considerando a estratégia 1.6, referente à meta 1 , o PNE prevê a implantação de avaliação da primeira etapa da educação básica "[...] a ser realizada a cada dois anos, com base em parâmetros nacionais de qualidade, a fim de aferir a infraestrutura física, o quadro de pessoal, as condições de gestão, os recursos pedagógicos, a situação de acessibilidade, entre outros indicadores relevantes" (BRASIL, 2014, p. 2). Como medidas mais recentes da efetivação dessa política, destacamos o Decreto $n^{\circ} 9.432$, de 29 de junho de 2018, que regulamenta 
a Política Nacional de Avaliação e Exames da Educação Básica, o qual, em seu Art. $5^{\circ}$, inclui, explicitamente, a Educação Infantil como integrante do Sistema de Avaliação da Educação Básica (SAEB); e a Portaria no 366, de 29 de abril de 2019 que estabelece as diretrizes de realização do SAEB no ano de 2019. Cabe demarcar que apenas algumas instituições de Educação Infantil participarão da aplicação de questionários.

Em um cenário atual, marcado por ameaças a inúmeros direitos conquistados, acentuamos ${ }^{1}$ nossa posição de enfrentamento e resistência ao conjunto de disputas existentes no campo da Educação Infantil quando pautamos a questão da avaliação na primeira etapa da educação básica. Compreendemos que esse panorama se compõe com " [...] inúmeros fatos históricos, não se constituindo exclusivamente no bojo das questões educacionais, mas circunscrito à história das crianças, das famílias trabalhadoras, da formação docente, das políticas públicas, de determinantes econômicos e sociais" (VIEIRA; CÔCO, 2018, p. 233).

Assumindo nossa responsividade com essa bandeira de luta e acreditando na força das interações vivificadas entre os sujeitos que atuam nas instituições de Educação Infantil, buscamos compreender, nesse âmbito, como vivenciar um processo avaliativo que, mesmo compondo um contexto de regulação e controle, consiga reunir esforços para o combate às desigualdades e para o fortalecimento de processos democráticos. Reafirmando o fortalecimento do trabalho conjunto, destacamos a construção da Conferência Nacional Popular de Educação (CONAPE) como um processo coletivo de articulação de entidades da sociedade civil que defendam a educação pública democrática. Dentre os 14 itens do Plano de Lutas dessa conferência está demarcada a defesa de

[...] uma avaliação da qualidade que amplie o conceito de resultados para além das proficiências em testes padronizados, ampliando-se o leque de indicadores, promovendo e viabilizando iniciativas de avaliação institucional participativa e fortalecendo o caráter diagnóstico, pedagógico e formativo de avaliação na educação básica e na educação superior (CONFERÊNCIA NACIONAL POPULAR DE EDUCAÇÃO, 2018).

Diante da trajetória de estudos, debates e proposições acerca da avaliação na/da Educação Infantil “[...] há uma questão de fundo voltada à perspectiva de

1 Com ancoragem no conceito de alteridade (BAKHTIN, 2011) e concebendo a pesquisa como processo construído coletivamente entre os diferentes sujeitos envolvidos, enunciamos as ações com verbos na $1^{\mathrm{a}}$ pessoa do plural. 
democracia, ou seja, de que maneira as tensões acerca da relação entre projeto de Educação Infantil e avaliação no Brasil têm se confrontado e dialogado no contexto das instituições e sujeitos envolvidos" (SOUZA, 2013, p. 115). Nesse contexto, concebemos a avaliação institucional na Educação Infantil como um percurso que " [...] envolve, em posições de paridade, diversos grupos de interesse e diversas perspectivas, usando debate e o conflito entre posições diversas de maneira construtiva, através de formas de negociação" (BONDIOLI, 2013, p. 37). Com isso, buscamos destacar sua dimensão formadora, articulada à defesa da garantia do direito à educação.

Para a organização de nossas palavras, estruturamos o artigo em quatro movimentos que se seguem a esta introdução. Inicialmente, compartilhamos a trajetória metodológica percorrida com a produção, sistematização e análise dos dados. Em seguida, abordamos os movimentos dialógicos que sustentaram a realização da avaliação institucional no contexto pesquisado. No terceiro movimento, tematizamos a dimensão formativa do ato de avaliar, mobilizada nos processos dialógicos vinculados à afirmação do direito à educação das crianças. Finalizando o artigo, apresentamos reflexões visando à continuidade da tematização voltada às práticas de avaliação institucional na Educação Infantil, advogando a participação de todos os sujeitos envolvidos na dinâmica educativa.

\section{Percursos metodológicos ${ }^{2}$}

As análises compartilhadas com esta produção derivam de pesquisa situada no contexto da Educação Infantil que focaliza as dinâmicas formativas vivenciadas por docentes em um processo de avaliação institucional. ${ }^{3}$ Ancorada em referenciais teórico-metodológicos bakhtinianos (BAKHTIN, 2009, 2010, 2011) e articulada à opção metodológica de abordagem qualitativa e de caráter exploratório, essa investigação focaliza as ressonâncias da avaliação institucional nos processos de formação continuada docente. Busca, com isso, compreender

2 Alguns trechos desta seção compõem o artigo Pesquisa em Educação: desafios teórico-metodológicos e contribuições da perspectiva bakhtiniana, publicado em 2017. Disponível em: https://online.unisc.br/seer/index.php/reflex/article/view/9707/pdf.

3 Este artigo integra a pesquisa "Avaliação institucional na Educação Infantil: percursos formativos", que compõe o conjunto de estudos desenvolvidos pelo Grupo de Pesquisa Formação e Atuação de Educadores (Grufae), vinculado ao Programa de Pós-Graduação em Educação (PPGE), do Centro de Educação (CE) da Universidade Federal do Espírito Santo (UFES). Mais informações podem ser consultadas em: http://dgp.cnpq.br/dgp/ espelhogrupo/6306517212901733. 
as relações que se constituem entre a avaliação institucional na primeira etapa da educação básica e os diferentes percursos de formação continuada vivenciados por docentes atuantes em dois dos 46 Centros Municipais de Educação Infantil (CMEI) integrantes do contexto municipal pesquisado. Para isso, desenvolvemos procedimentos de análise documental e entrevistas semiestruturadas.

No escopo deste artigo, dialogamos especialmente com os dados produzidos a partir das entrevistas semiestruturadas realizadas com as onze docentes ${ }^{4}$ participantes da pesquisa desenvolvida. Na composição do grupo, contamos com quatro professoras, três pedagogas, duas assistentes de Educação Infantil e duas diretoras. Os dados de perfil das participantes indicam um grupo formado principalmente por mulheres, casadas, acima dos 40 anos de idade, com formação acadêmica em nível de especialização e com experiência no campo da Educação Infantil de mais de dez anos de atuação. A renda pessoal se concentra na faixa de cinco a sete salários mínimos e a atuação exclusiva na área da educação é relativa a cinco das onze docentes. Em relação a seis participantes que declararam já ter desenvolvido outras atividades, no período de realização da pesquisa, informaram que atuavam exclusivamente na área da educação.

As entrevistas foram desenvolvidas nos meses de dezembro de 2014 a abril de 2015, com dinâmicas individuais com sete docentes e em duplas com as outras quatro. Esse desenvolvimento metodológico se efetivou conforme a disponibilidade das trabalhadoras, equacionando desejo de participação, disponibilidade de tempo e intensidade dos trabalhos nas instituições. Em respeito ao princípio ético de confidencialidade da identidade das participantes, para organização dos dados produzidos, optamos pela nomeação codificada das docentes de acordo com suas diferentes atuações. Com isso, foram atribuídas letras em ordem alfabética para cada função, correspondente à ordem temporal inversa à realização das entrevistas. Quanto à questão de que as docentes atuavam em instituições diferentes, nossa opção foi reuni-las num só grupo, sem localizar cada CMEI. Assim, temos como participantes as pedagogas A, B, C; as professoras A, B, C, D; as assistentes de Educação Infantil A, B; e as diretoras A, B. Essa decisão se justifica tanto pela confidencialidade de suas identificações quanto pela compreensão do princípio de que as relações dialógicas se materializam entre sujeitos distantes no tempo e no espaço, desde que conservem algum ponto de contato entre si (BAKHTIN, 2011).

Ressaltamos que a interlocução com as docentes por meio das entrevistas nos permitiu conhecer os processos de formação continuada vivenciados e dia-

4 As referências a essas participantes, no decorrer do texto, serão feitas sempre no feminino, não apenas para demarcar a condição de maioria feminina no grupo de participantes desta pesquisa, mas também no campo da Educação Infantil no município pesquisado e no Brasil, de modo geral. 
logar sobre seus pontos de vista a respeito da avaliação institucional. Durante a realização desse procedimento, nós nos colocamos em diálogo numa perspectiva de formação recíproca, mantendo nossa atitude responsiva na condução ética da pesquisa. Ao conduzirmos as entrevistas em consonância com o percurso enunciativo de cada participante, em alguns momentos, com apenas uma pergunta, inúmeras questões emergiam no encadeamento das ideias e enunciados compartilhados, contemplando e inserindo outros itens no roteiro. Na sequência do procedimento, as entrevistas foram transcritas na ordem exata das falas, tanto da pesquisadora como das docentes, com a identificação de cada CMEI, a data, os nomes e as funções de cada docente, produzindo cerca de 80 páginas de texto.

Para a leitura dos sentidos produzidos a partir dos enunciados das entrevistas, inicialmente recorremos aos pressupostos da análise de conteúdo (BARDIN, 2011), em especial às etapas de pré-análise e exploração do material. Quanto às interpretações e inferências, buscamos suporte teórico-metodológico em concepções bakhtinianas que nos sustentam na compreensão dos dizeres das participantes, reunindo-os em torno das questões discutidas durante as entrevistas e dialogando com os enunciados na perspectiva de aproximações e distanciamentos entre seus posicionamentos. Nesse intento, seguimos com o propósito de conhecer os processos de formação continuada vivenciados e os distintos pontos de vista das docentes a respeito da avaliação institucional.

\section{Avaliação da Educação Infantil: um encontro em dois movimentos dialógicos}

Iniciamos os diálogos com as docentes indagando sobre o primeiro movimento do processo avaliativo institucional, em que os participantes se reuniram em sete grupos ${ }^{5}$, cada um responsável por dimensões específicas da avaliação da qualidade do atendimento às crianças. ${ }^{6}$ Sobre esse movimento, as docentes

5 De acordo com a metodologia do documento Indicadores da Qualidade na Educação Infantil Pública do município pesquisado, seguindo a proposta do documento do MEC (BRASIL, 2009b), no primeiro momento da realização da avaliação institucional, os participantes se dividem em grupos e analisam alguma(s) dimensão(ões) com seus indicadores e questões. Simultaneamente outros grupos analisam outra(s) dimensão(ões) (MUNICÍPIO, 2012, p. 33).

6 As sete dimensões definidas são: Planejamento e gestão educacional; Práticas pedagógicas; Interações; Promoção da saúde; Espaços, mobiliário, equipamentos e materiais; Formação e condições de trabalho dos professores e demais profissionais; Cooperação e troca com as famílias; Participação na rede de proteção social. Articulados a sete dimensões, o instrumento avaliativo reúne 26 indicadores com 126 questões. 
evidenciaram questões atinentes à participação dos sujeitos nos processos de discussão e à importância do conhecimento antecipado dos indicadores e itens constantes no instrumento avaliativo.

Pesquisadora: Como se desenvolveram as discussões na sala em que você participou?

Professora B: Houve um envolvimento de todo mundo; falando especificamente, houve uma seriedade. Eu não percebi ninguém fazendo "corpo mole" [risos]. As pessoas estavam engajadas realmente em avaliar. Pela minha percepção, estando à frente da coordenação, a gente identificava pessoas que queriam realmente compreender os critérios de avaliação, as cores, e... Sim, houve uma discussão.

Professora D: [...] Ai foi mais tranquilo porque todo mundo já sabia do que se tratava, houve esse preparo, e eu me lembro que foi mais amarrando mesmo... fechando... e não teve esse conflito... foi mais na formação [referindo-se à etapa de planejamento da avaliação institucional em que emergiam muitas dúvidas e divergências].

As docentes ressaltaram, portanto, o engajamento, a seriedade e o interesse em compreender o processo avaliativo, destacando a formação como um preparo que possibilita mais tranquilidade e segurança aos participantes. Ao considerar que os conflitos tinham acontecido em encontros de formação que antecederam o dia da avaliação, problematizamos a importância de entender os dissensos e as discordâncias como integrantes dos processos avaliativos e formativos, reconhecendo-os como desafios e evitando que sejam considerados como impeditivos de processos dialógicos.

Conforme mencionado pelas docentes, o envolvimento, a participação, o posicionamento dos sujeitos, por vezes divergentes, têm grande significado quando se pretende realizar a avaliação institucional em uma perspectiva coletiva. Nesse conjunto de fatores intervenientes que promovem possibilidades de um processo democrático, inclui-se o instrumento que orienta as questões que são avaliadas.

Sobre essa questão, importa ressaltar que a proposta de elaboração do instrumento avaliativo foi embasada em princípios de trabalho coletivo e sistematizada pelo Núcleo de Pedagogas ${ }^{7}$, em movimentos de escuta que envolveram

7 Refere-se a um grupo composto por pedagogas da Rede Municipal que se interessaram pelo trabalho a partir de convite da equipe de educação infantil da Secretaria Municipal de Educa- 
outros sujeitos. Nesse direcionamento, indagamos as docentes acerca de seus pontos de vista sobre o contato com o texto do instrumento antes do dia da avaliação e os sentidos desse conhecimento antecipado.

Pesquisadora: No caso, você conhecia as questões que seriam avaliadas antes do dia da avaliação? Você já conhecia o instrumento?

Professora A: Sim, por conta da formação, eles [provavelmente referindo-se ao Núcleo de Pedagogas] apresentaram pra gente.

Pesquisadora: Como você avalia isso, [fala o nome da docente]? Conhecer o instrumento antes é importante?

Assistente A: Faz a gente pensar um pouquinho mais, para nos prepararmos e refletir mais, para a gente, na hora, não sermos [sic] pegas de surpresa e falar qualquer coisa que vem logo à mente. Coloca a gente para pensar mais. Acho bacana.

Diretora B: Conhecer antes é muito bom porque você vai preparando algumas questões e observando mais, e a gente fez isso. É tanto que a gente conhecia e a gente mexeu nas questões e fazia sugestões, então eu acho que isso ajuda bastante; com isso você já tem outro olhar para a escola.

Desse modo, elaborar coletivamente o instrumento e compartilhar a versão definida com as participantes se articula à possibilidade de, antes mesmo da avaliação propriamente dita, os sujeitos se envolverem em uma dinâmica de mais atenção às situações específicas que pretendem analisar. Assim, as docentes enfatizam a necessidade de conhecer antecipadamente o instrumento avaliativo, ainda que não tenham participado de sua elaboração. Sobre essa perspectiva, Moro; Souza (2014, p. 122) realçam a importância de que, ao se avaliar o contexto da instituição de Educação Infantil, os instrumentos devem " [...] contar com a validação consensual dos envolvidos, independentemente de se tratar de instrumentos já existentes ou de instrumentos a serem construídos ad hoc".

As falas das entrevistadas assinalam, ainda, o quanto esse conhecimento prévio confere segurança, familiaridade e aproximação às questões eleitas como prioridade para aquele momento de avaliação. Tais elementos se distanciam da lógica avaliativa baseada no inesperado, na surpresa, no sentimento de que não sabemos o que será perguntado e qual a resposta esperada e se aproximam da

ção - SEME, por integrantes da equipe da Gerência de Educação Infantil/SEME e por uma técnica da Assessoria Técnica de Planejamento da SEME. 
avaliação que concebe "[...] a participação como ação política que mobiliza contradições e que, portanto, requer que a elaboração do instrumento não se caracterize somente como um formulário a ser preenchido em atendimento a alguma exigência burocrática" (VIEIRA; CÔCO, 2019, p. 610).

Quando discutimos o primeiro movimento de avaliação, uma das entrevistadas relatou que, no grupo em que estava, se decidiu por não atribuir critério "ótimo" " a nenhuma das questões ou indicadores, ainda que assim fosse considerado, combinando um critério próprio para conseguir visibilidade da Secretaria Municipal de Educação (SEME). Essa decisão exprime uma compreensão de que o órgão central prioriza cenários problemáticos, e não situações indicadas pelos CMEI como em um bom processo de melhoria da qualidade. Esse relato indica, ainda, a ideia de corresponsabilidade da SEME no apoio às instituições de Educação Infantil.

Podemos entender que, para esses participantes, os resultados da avaliação institucional incidem sobre as decisões e prioridades do órgão central quanto às ações de apoio aos CMEI. Então, embora a avaliação seja voltada à realidade da instituição de Educação Infantil, os participantes trazem para esse momento a interlocução com a equipe da SEME, demonstrando conhecer os entrelaçamentos desse complexo processo que envolve os contextos de produção de textos na política e o contexto das práticas (BALL, 2001, 2009), conforme indica o documento que propõe subsídios para a sistemática de avaliação da Educação Infantil:

Os resultados da avaliação institucional, produzidos pelos estabelecimentos educacionais, interpretados em seu conjunto, trazem pistas para a definição de prioridades e formulação de políticas educacionais; do mesmo modo, as avaliações das redes municipais de ensino iluminam as decisões em âmbito do Ministério da Educação (BRASIL, 2012, p. 20).

Cabe assinalar, ainda, que a atribuição de conceitos ótimo, bom e regular não faz parte dos critérios avaliativos. Ainda assim, essas expressões são citadas para informar a diferença na avaliação de algum indicador quando levado para análise na plenária. No diálogo com esses enunciados, nossas problematizações alcançam três vertentes analíticas: i) a limitação de qualquer instrumento que se propõe a estabelecer critérios para um processo avaliativo, sejam quais forem as nomenclaturas, códigos, escalas ou índices de qualquer ordem, visto

8 Provavelmente a docente se refere à cor azul, que na codificação utilizada no município significa que "o processo de melhoria da qualidade já está num bom caminho" (VITÓRIA, 2012, p. 33). 
que os sujeitos ativos e falantes se apropriam desses códigos, não levando em conta o significado explícito em documentos e instrumentos, mas sim os seus sentidos; ii) a força do pertencimento dos sujeitos ao grupo quando interagem e se constituem como coletivo, evidenciando que o indivíduo "[...] se sente parte indissolúvel da coletividade, membro do grande corpo popular" (BAKHTIN, 2013 , p. 222), pois a docente expressa que o conceito "bom" foi apropriado pelos participantes do grupo ao se referir a ele como nosso; iii) a escuta de contrapalavras e o exercício da heteroglossia no momento em que a análise desenvolvida por um grupo de participantes se confronta com os pontos de vista de outros participantes e não coincidem, vivificando o movimento dialógico que pode encontrar, no excedente de visão do outro, possibilidades para sua completude, ainda que sempre inconclusa (BAKHTIN, 2011).

Pesquisadora: E em relação à plenária? O que vocês pensam sobre essa metodologia? Falem um pouquinho de como vocês vivenciaram isso.

Assistente B: Eu acho que traz uma praticidade. Porque, se levarmos todos os pontos para plenária, é uma discussão muito longa, então, quando a gente vai pra sala e traz meio caminho andado, acho que já adianta. Acho que não haveria tempo pra ser discutido de forma ampla.

Professora A: A única coisa que não foi legal foi o tempo. Nós precisávamos de mais tempo, porque teve uma hora que demos uma corridinha pra irmos pra plenária. E a plenária não foi rápida e esvaziou um pouco... já eram 10 horas da noite! Acho que deveria ter sido uma programação de um tempo, por exemplo, uma manhã inteira. Aliás, uma manhã não, porque na outra escola eu participei no vespertino e foi uma tarde inteira e também não deu, também foi correria. Deveriam ter sido dois dias. Um dia de discussão e avaliação e no outro dia a plenária.

Pesquisadora: Então, você... por ter vivenciado esse processo, como você percebeu... o que você analisa dessa metodologia de discussão em grupos pequenos e na plenária?

Professora B: Eu acho produtivo porque você tem como levar para um grupo maior, ou para todos, um parecer. Acho produtivo, válido. É o que acontece normalmente quando trabalhamos com documentos. Tem-se a consulta pública que é apenas depois que se tem um grupo menor que vai construir o documento. Então, é a mesma lógica. Eu tenho um grupo menor que vai elaborar, que vai processar aquilo. 
Os enunciados sobre a dinâmica de avaliação desenvolvida em dois momentos indicam sua intricada relação com a dimensão temporal na perspectiva de garantir que os sujeitos, como falantes, possam expressar suas ideias, compreensões, dúvidas; enfim, vivenciar os movimentos desse encontro com mais possibilidades de diálogo sobre o processo de melhoria da qualidade do CMEI. Quando o tempo não é suficiente e ocorre o esvaziamento, em razão de as pessoas não poderem permanecer além do horário previsto, as discussões e debates podem ser comprometidos, assim como a produção dos dados sobre a qualidade que foi avaliada.

Cabe recordar que o instrumento avaliativo utilizado é composto por 126 questões relacionadas a 26 indicadores que se articulam às sete dimensões definidas. Considerando as análises das docentes, para superar a dificuldade de tempo evidenciada, os dados da pesquisa apontam que não seria necessário reduzir a quantidade de questões, indicadores ou dimensões do instrumento, tampouco alterar a dinâmica da avaliação, que foi planejada para acontecer em dois movimentos diferenciados; mas sim proporcionar mais tempo de interação entre os sujeitos que se dispõem a avaliar a qualidade da instituição de Educação Infantil.

Com relação ao segundo movimento desse encontro avaliativo, as docentes expressaram sua visão geral sobre a situação da qualidade no CMEI ao concluírem a avaliação institucional:

Pesquisadora: Você conseguiu perceber, após as discussões na plenária, como ficou a avaliação geral do CMEI? Qual a ideia que ficou pra você?

Professora A: Que a gente estava em um ótimo caminho. Não estava ótimo porque a gente não queria que estivesse ótimo. Nós queríamos repensar algumas coisas para melhorar, principalmente na questão do espaço físico, das coisas que não dependem da nossa boa vontade. Depende sim, a gente tem planejamento, tem programação, $\underline{\text { mas tem o }}$ sistema também [ênfase; grifo nosso].

Assinalamos, no diálogo com a docente, que, embora não dispusessem dos dados organizados para a fase de análise de forma mais detalhada, ao final da avaliação institucional seria possível empreender uma visão geral da qualidade avaliada no CMEI naquele dia. Salientamos que, como todo movimento dialógico, diferentes pontos de vista se encontram, ora aproximando-se ora rivalizando-se, convocando outros encontros. 
$\mathrm{Na}$ intenção de que esses outros encontros sejam viabilizados para a efetivação do processo avaliativo, precisamos atentar para a importância da participação. Essa é uma condição primordial quando apostamos numa concepção educativa que exige, para sua realização, "[...] o envolvimento ativo de uma pluralidade de sujeitos: não somente os professores, mas também as famílias, as crianças ou os estudantes e, em um âmbito sistêmico mais amplo, a sociedade civil no seu conjunto" (BONDIOLI, 2013, p. 40).

Concordando com essa perspectiva plural, precisamos desafiar-nos a incluir as crianças nesse movimento com vistas à escuta de suas necessidades, de seus pontos de vista, dispondo-nos a conversar sobre o que desejam, buscando compreender suas respostas e suas propostas, assunto também debatido com as entrevistadas.

Pesquisadora: E com as crianças? Foi feito algum tipo de trabalho? As crianças sabiam o que estava acontecendo?

Professora C: Sabiam! [ênfase] A gente fazia uma dinâmica pra elas das coisas que elas "gostam e não gostam". Para os maiores, a gente fez em forma de desenho, para eles relatarem desenhos das coisas que eles gostavam. Já os pequenos, a gente não conseguia pegar isso, mas a gente, de alguma forma, tentou fazer esse trabalho.

Pedagoga C: [...] eu creio que a gente poderia ter feito melhor com as crianças e também que faltou uma orientação desse trabalho com as crianças... até no grupo de pedagogos. Eu creio também que não teve essa ênfase que deveria ser dada... assim [pausa maior].

Cientes ações que envolvem viabilizar a participação das crianças no processo de avaliação institucional e em diálogo com o que expressam as docentes, argumentamos que os avanços nessa questão estão sendo conquistados com investimentos em diferentes ações e iniciativas, inclusive no campo das pesquisas.

A respeito dessa temática, Richter; Barbosa (2011) afirmam o compromisso da Educação Infantil com uma ética da responsabilidade, na qual os adultos têm obrigações inerentes à alteridade das crianças, como a atenção para uma escuta dos seus dizeres. Problematizando a concepção de qualidade como “[...] um conceito relativo que deve surgir de um debate democrático e ser constantemente revisto", Campos (2013, p. 41) realça que a implementação de práticas de qualidade com as crianças pequenas requer que seja considerado o contexto em que os sujeitos envolvidos estão inseridos em alinhamento com suas vivên- 
cias cotidianas e alerta sobre o respeito às necessidades e ao protagonismo das crianças como elementos primordiais nos debates.

Com o intuito de garantir a participação das crianças, o documento Indicadores da Qualidade na Educação Infantil Pública de Vitória ressalta a iniciativa do projeto "Fala Criança", que conta com a participação das crianças dos grupos finais da Educação Infantil, professores, pedagogos e diretores das unidades de ensino e profissionais da SEME Central e da Prefeitura Municipal.

\begin{abstract}
Para promover as discussões na Unidade de Ensino, a SEME Central sugere ações pedagógicas lúdicas com histórias, músicas e atividades que tratam os temas mobilização, trabalho coletivo, entre outros. Nesse movimento, as crianças escolhem seus representantes, bem como definem quais aspectos da realidade local serão levados para o fórum "Fala Criança”. As crianças apresentam as proposições e, posteriormente, recebem a devolutiva (VITÓRIA, 2012, p. 20).
\end{abstract}

Observamos, também, que as iniciativas mencionadas acima são direcionadas às crianças da faixa etária de 4 e 5 anos, desafiando nossa ação de possibilitar a participação das crianças de 0 a 3 anos. Reconhecemos que a pesquisa com crianças constitui desafio no campo da Educação Infantil (CRUZ, 2008), exigindo estudos e conhecimentos metodológicos que, para além de uma escuta atenta e sensível das vozes infantis, subsidiem-nos para vivenciar com elas movimentos dialógicos, com possibilidades de réplicas, concordâncias, discordâncias, e silenciamentos (BAKHTIN, 2009, 2011), diante do desafio do ato de avaliar e, sobretudo, de sua dimensão formativa, que analisamos a seguir.

\title{
A dimensão formativa do ato de avaliar
}

Durante a interlocução sobre os dois movimentos dialógicos que integram o dia de realização da avaliação institucional, a formação emergiu em diversos enunciados como parte relevante do processo avaliativo. Avançando nessa dinâmica, abordamos a dimensão formativa do ato de avaliar que nos remete à concepção de responsividade (BAKHTIN, 2010), reconhecendo, simultaneamente, nossas singularidades como sujeitos e a necessidade do outro para nossa constituição e formação. 
Nesse sentido, defendendo uma avaliação institucional fundamentada em princípios de inclusão, de diálogo e de construção da autonomia, indagamos as docentes a respeito de sua participação no dia da avaliação institucional.

Pesquisadora: E nesse processo, como analisa sua participação?

Assistente A: Bacana! Sempre que eu me recordava de alguma coisa que achava necessário falar, geralmente eu falava ou discutia com alguém do lado: "Lembra disso? Acho que não é assim não", e aí acabávamos comentando...

Professora A: Então... a minha expectativa era muito grande, e eu participei com empolgação desse sistema, achei legal! Acho que a gente... avaliar a prática... refletir... ajuda a ter novas perspectivas. E também, no dia, eu tentei participar da melhor maneira possivel. Eu me sinto um pouco... [pausa] como posso dizer? Eu participei muito da construção dessa Educação Infantil! [ênfase]

Essas docentes evidenciam sua participação no dia da avaliação institucional, realçando a importância da interlocução com o outro e da responsabilidade com esse processo ao mencionarem fatos como "discutia com alguém do lado" e "eu participei muito dessa Educação Infantil". No que tange aos princípios de trabalho coletivo, concordamos que:

[...] a participação não é um conceito abstrato como um "direito" ou um "dever", mas é um compromisso entre pessoas, que se traduz em sinergia de ações; tem, portanto, sempre uma conotação local e histórica, ligada a precisos momentos de uma escola ou de um contexto educativo e a participantes concretos (BONDIOLI, 2013, p. 41).

Em uma perspectiva de trabalho coletivo situado social e historicamente, que necessita da participação de todos os envolvidos para se concretizar, indagamos às docentes acerca dos processos de interação e de discussão entre os participantes na plenária.

Pesquisadora: Na plenária, como você analisa a interação e o processo de discussão entre os participantes? 
Professora D: Com respeito! Porque eu me lembro que tinha que fazer inscrição pra poder falar e era dada a vez, e tinha a questão do tempo também. Eu acho que foi uma coisa democrática dentro da possibilidade de escuta. Eu me lembro que estava um dia muito quente... e as pessoas iam chegando... e eu vejo uma coisa muito sistematizada, com toda a organização possível...

Professora A: [...] tanto que teve uma pessoa de outro CMEI que veio para o nosso CMEI no outro dia, já que eram em dias diferentes, para ver a dinâmica [referindo-se ao dia da avaliação institucional]. Ela chegou aqui e falou: "Nossa! Tinha pensado: assim dá certo". E as meninas... tem uma coisa, a [fala o nome da pedagoga] tem uma forma de organizar! Ou era [fala o nome da diretora] na direção, se eu não me engano. Elas fizeram um programa de ação muito interessante. Então outras pessoas quiseram conhecer para aplicar.

Nessa abordagem, os enunciados das docentes indicam que as interações alcançam profissionais de outra instituição de Educação Infantil, potencializando processos formativos no contexto das práticas avaliativas. Uma prática rememorada em sua organização, nas relações de respeito, no reconhecimento do exercício de colegas da equipe de trabalho, em sentidos constituídos coletivamente e com as crianças; sentidos que, conforme a docente ressalta, são preservados e compartilhados com novos profissionais que chegam depois. Sendo assim, concordamos com Freitas et al. (2009, p. 38) quando asseveram que "A avaliação institucional carrega, em si, a potência de nos fazer lembrar o compromisso pessoal com o projeto coletivo".

As expectativas postas à avaliação institucional, de acordo com Freitas et al. (2009), concentram-se, geralmente, na localização de problemas e contradições da instituição pelos profissionais ou pela comunidade escolar, que assumem, na sequência, compromissos com a melhoria ou superação dessas dificuldades na própria instituição, ou recorrem a outras instâncias na busca de soluções. Encaminhando a prática avaliativa de âmbito institucional ao escopo da Educação Infantil, concordamos que a avaliação é uma prática que

[...] permite à instituição educativa refletir sobre si, sobre sua identidade, verificando e consolidando consensos acerca de seu próprio projeto; a ênfase ao caráter formativo da avaliação de determinado contexto, o que potencializa a criação de percursos de melhorias, em detrimento do juízo final acerca dos resultados (MORO; SOUZA, 2014, p. 122). 
Nessa direção, assinalamos que a dimensão formativa da avaliação institucional requer nossa compreensão do outro como sujeito singular, insubstituível (BAKHTIN, 2010). Bakhtin (2011, p. 23) ainda argumenta sobre a necessidade de "[...] entrar em empatia com esse outro indivíduo, ver axiologicamente o mundo de dentro dele tal qual ele o vê, colocar-me no lugar dele e [...] criar para ele um ambiente concludente a partir desse excedente da minha visão [...]". Trata-se, nesse contexto, de um processo constitutivo no qual o ponto de vista do outro possibilita completar a percepção de $\operatorname{mim}^{9}$ mesmo, uma vez que, do meu lugar, não consigo ver-me inteiramente, precisando do excedente de visão do outro. Desse modo, compreendemos que o excedente de visão implica uma dimensão ética, pois, ao buscar situar-me no lugar do outro, comprometo-me responsivamente em contribuir com algo que somente eu, do lugar que ocupo, posso ver.

Nesse percurso, buscamos dialogar também sobre como as docentes percebem alguma contribuição formativa mediante as vivências com a avaliação institucional.

Assistente A: Coisas que a [fala o nome da assistente de Educação Infantil] está vendo, vivenciando, só que eu não tenho nem ideia. Às vezes não temos oportunidade de comentar sobre algumas coisas por causa da correria... Enfim, fez [referindo-se à avaliação institucional] com que nós olhássemos com mais carinho e com mais atenção para coisas que geralmente não ficávamos atentas.

Professora D: Eu acho que trouxe essa contribuição. Inclusive foi dando o horário e nós fomos ficando, até porque a gente não queria se ausentar.. naquele momento ali seria importante. E ao mesmo tempo quebrou aquele tabu de medo, porque muitas vezes as pessoas ficam receosas quando se trata de um documento. E eu, que tive a oportunidade de participar do "novo olhar" [referindo-se ao documento orientador do município], na época da professora [fala o nome da professora que coordenou a elaboração do documento]... E as pessoas, elas se distanciam com medo de dar opinião. E esse movimento foi uma coisa que envolveu a todos. Então, não tinha onde você falar assim: eu posso, você não pode, eu posso, ela não pode! Foi dada essa abertura a todos, e eu vejo como uma coisa que poderia acontecer de novo e que seria bem-vindo daqui um tempo, fazer essa nova avaliação, saber como está e como ficou definido, porque eu achei muito bom!

9 Mantemos, em algumas partes do texto, a referência à primeira pessoa do singular como na obra do autor, realçando a condição singular de cada um de nós no ato responsivo diante do outro. 
Ao abordar a formação de professores em meio à complexidade do trabalho na escola, Nóvoa (2009) aponta a importância dessa formação como espaço da análise partilhada das práticas. Ele acrescenta que "[...] não há respostas feitas para o conjunto de dilemas que os professores são chamados a resolver numa escola marcada pela diferença cultural e pelo conflito de valores" (NÓVOA, 2009 , p. 41), ressaltando, por isso, o valor da ética profissional que se constrói no diálogo com os colegas.

Assim, o processo de formação continuada, entre outras características, "[...] precisa centrar-se nos problemas da escola, [...] mobilizando conceitos, teorias, métodos no contexto concreto de uma reflexão profissional" (NÓVOA, 2009 , p. 41). Concordando com essa premissa sobre a formação continuada, reafirmamos a dimensão formativa da avaliação institucional como um processo fundamentado no reconhecimento de autoria e autonomia dos envolvidos e dos movimentos de resistência como elementos constituintes dos processos dialógicos. Todavia, com o referencial bakhtiniano, devemos contrastar a perspectiva de uma polifonia (que festeja a possibilidade de reunir múltiplas vozes) com a - nem sempre evidente - força da heteroglossia, que se associa às "profundas clivagens estruturais da vida social" (STAM, 1993, p. 167).

Situando nossas palavras, enfatizamos que a avaliação institucional, em sua dimensão formativa, pressupõe o encontro entre os sujeitos que compartilham um contexto comum. Sendo assim, os movimentos precisam ser intensamente dialógicos, exigindo de nós o afastamento de uma avaliação à revelia e nos convocando à aproximação das vivências de compartilhamento em que não há uma última palavra, em que as contradições, discordâncias e contrapalavras alimentam o processo dialógico de nossa constituição humana.

\section{Considerações finais}

O diálogo com enunciados docentes acerca de suas vivências em um processo de avaliação institucional na dinâmica de duas instituições de Educação Infantil e a ênfase na dimensão formativa dessa ação avaliativa nos permitiram fomentar algumas reflexões no texto que ora compartilhamos. Direcionando nossos olhares para a realização da avaliação institucional, nossas interlocuções com as vozes das docentes evidenciaram que o dia desse evento foi um momento significativo de encontro dos adultos (familiares, docentes e demais profissionais) para debater e analisar a qualidade da Educação Infantil que é ofertada às crianças. Embora nesse dia as crianças não estivessem nas instituições, o com- 
partilhamento das ideias e opiniões sobre a qualidade nas dimensões avaliadas e sobre o envolvimento dos diversos atores responsáveis pela educação estava centrado em ações relativas às suas infâncias.

Quanto aos percursos formativos das docentes participantes, compreendemos que dialogam com as singularidades das vivências formativas constituídas nas distintas interpretações que cada uma faz sobre sua participação no processo como ser único, irrepetível. Assim, ainda que relatem vivências relacionadas a um evento comum de avaliação, as impressões, as assimilações e as compreensões, em sua condição ilimitada, produzem infinitos sentidos que vivificam a existência singular de cada sujeito, em especial, no estabelecimento de compromissos com os processos educativos, implicados com a participação na pauta da educação.

Dada a complexidade dos sentidos implicados às decisões de quem, quando e em quais momentos cada um participa das ações formativas, concebemos a participação como ação política. Nesse sentido, é possível problematizar que a avaliação institucional não se efetiva apenas por meio da reunião de pessoas em um mesmo espaço, ao mesmo tempo e em torno de um único instrumento avaliativo. Faz-se necessária a observância de que os laços construídos nas diversas interações cotidianas das instituições de Educação Infantil, que precedem esse momento específico para avaliar a qualidade, são primordiais na promoção de encontros dialógicos e marcam a continuidade dos trabalhos, ecoando nas mais diversas ações implicadas com a garantia do direito à educação.

Segundo as docentes, a metodologia de reuniões em pequenos grupos e posterior discussão na plenária com o conjunto dos participantes contribuiu para os diálogos entre os envolvidos, encerrando grande potencial formativo. No entanto, as entrevistadas sinalizaram a necessidade de mais tempo para esses debates, com o intuito de escapar do aligeiramento das discussões que se efetivam nas interações entre os sujeitos. Como perspectiva de fortalecimento dessas interações, é preciso buscar possibilidades de inclusão das famílias e das crianças de forma a potencializar sua participação.

Com essas interlocuções, reiteramos a relevância das iniciativas que tenham como premissa a participação dos envolvidos na dinâmica avaliativa e formativa das instituições de Educação Infantil. Essas são iniciativas que, em condições dadas e enfrentando desafios, caminham no horizonte da necessidade de investir em ações que, valorizando a Educação Infantil, respeitem sua especificidade.

Com isso, demarcamos ainda a importância de problematizar a agenda da avaliação que tem buscado hegemonia no campo social, impondo testes padronizados aos estudantes, reverberando em mecanismos de controle, propondo iniciativas de ranqueamento das instituições, estabelecendo padrões de 
desenvolvimento às crianças, determinando imposições aos professores e limitações aos currículos e infligindo fragilidades aos atos educativos. Buscamos, com este texto, diante dos enfrentamentos necessários, pautar a avaliação na direção das possibilidades de dizer, da possibilidade de agregar a presença dos distintos sujeitos que compõem os processos educativos e, sobretudo, evidenciar a multiplicidade de vozes que, guardando necessidades próprias, precisam ter garantido seu espaço de expressão, fortalecendo a educação como um contexto de práticas democráticas.

Sabendo dos estratagemas dos discursos pseudopolifônicos, sobretudo quando as imposições incidem sobre as crianças (que negociam suas necessidades em meio a um adultocentrismo reinante), realçamos que a pauta da avaliação integra uma disputa viva no contexto atual. Portanto, precisa de contínuo acompanhamento, a partir dos diagnósticos e das proposições em debate. Assumimos, por fim, o inacabamento das reflexões propostas, expresso nos limites das interpretações compartilhadas; mantemos, desse modo, nossa disposição a outras interlocuções e convidamos às contrapalavras que nutrem a cadeia dialógica no campo da avaliação institucional na primeira etapa da educação básica.

\section{REFERÊNCIAS}

BAKHTIN, M. Marxismo e filosofia da linguagem: problemas fundamentais do método sociológico da linguagem. Tradução de Michel Lhud e Yara Frateschi Vieira. 13. ed. São Paulo: Hucitec, 2009.

. Para uma filosofia do ato responsável. Tradução de Valdemir Miotello e Carlos Alberto Faraco. São Carlos: Pedro \& João, 2010.

. Estética da criação verbal. Tradução de Paulo Bezerra. 6. ed. São Paulo: Martins Fontes, 2011.

. Cultura popular na Idade Média e no Renascimento: o contexto de François Rabelais. Tradução de Yara Frateschi Vieira. 6. ed. São Paulo/Brasília: Hucitec, 2013.

BALL, S. J. Diretrizes políticas globais e relações políticas locais em educação. Currículo sem Fronteiras, v. 1, n. 2, p. 99-116, 2001.

. Entrevista com Stephen Joseph Ball: um diálogo sobre justiça social, pesquisa e política educacional. Entrevista concedida a Mainardes, J. \& Marcondes, M. I. Educação e Sociedade, Campinas, v. 30, n. 106, p. 303-318, jan./abr. 2009. 
BARDIN, L. Análise de conteúdo. São Paulo: Edições 70, 2011.

BONDIOLI, A. Construir compartilhando a qualidade: a contribuição das partes interessadas. In: BONDIOLI, Anna; SÁVIO, Donatella (Org.). Participação e qualidade em educação da infância: percursos de compartilhamento reflexivo em contextos educativos. Trad. Luiz Ernani Fritoli. Curitiba: Ed. UFPR, 2013. p. 25-49.

BRASIL. Educação Infantil: subsídios para construção de uma sistemática de avaliação. Brasília: MEC/SEB, 2012. Disponível em: http://portal.mec.gov.br/index. php?option $=$ com_docman\&view $=$ download \&alias $=11990$-educacao-infantil-sitematica-avaliacao-pdf\&Itemid=30192. Acesso em:|29 jun. 2013.

. Resolução n. ${ }^{\circ}$ 05, de 17 de dezembro de 2009. Fixa as diretrizes curriculares nacionais para a Educação Infantil. Diário Oficial [da] República Federativa do Brasil, Brasília, 18 dez. 2009a. Seção 1, p. 18. Disponível em: portal.mec.gov.br/index. php?option=com_docman\&task. Acesso em: 16 jul. 2013.

. Indicadores da Qualidade na Educação Infantil. Brasília: MEC/SEB, 2009b. Disponível em: http://www.portal.mec.gov.br/dmdocuments/indic_educ_infantil.pdf. Acesso em: 5 maio 2013.

. Lei n. ${ }^{\circ}$ 13.005, de 25 de junho de 2014. Institui o Plano Nacional de Educação e dá outras providências. Diário Oficial [da] República Federativa do Brasil, Brasília, 26 de junho de 2014. Disponível em: http://www.planalto.gov.br/legislacao. Acesso em: 29 jun. 2014.

. Decreto $n^{\circ}$ 9.432, de 29 de junho de 2018. Regulamenta a Política Nacional de Avaliação e Exames da Educação Básica. Disponível em: http://www.planalto.gov.br/ ccivil_03/_Ato2015-2018/2018/Decreto/D9432.htm. Acesso em: 19 jul. 2018.

. Portaria $n^{\circ} 366$, de 29 de abril de 2019. Estabelece as diretrizes de realização do Sistema de Avaliação da Educação Básica (SAEB) no ano de 2019. Disponível em: http:// www.in.gov.br/web/dou/-/portaria-n\%C2\%BA-366-de-29-de-abril-de-2019-86232542. Acesso em: 29 ago.2019.

CAMPOS, M. M. Entre as políticas de qualidade e a qualidade das práticas. Cadernos de Pesquisa, São Paulo, v. 43, n. 148, p. 22-43, jan./abr. 2013.

CÔCO, V. et al. O Plano Nacional de Educação: desafios no campo da Educação Infantil. EccoS-Rev. Cient., São Paulo, n. 37, p. 77-92, maio/ago. 2015.

CONFERÊNCIA NACIONAL POPULAR DE EDUCAÇÃO (CONAPE). Belo Horizonte, 2018.

CRUZ, S. H. V. Apresentação. In: CRUZ, Silvia Helena Vieira. A criança fala: a escuta de crianças e pesquisas. São Paulo: Cortez, 2008. p. 11-31.

FREITAS, L. C.; SORDI, M. R. L.; MALAVASI, M. M. S.; FREITAS, H. C. L. Avaliação educacional: caminhando pela contramão. Petrópolis: Vozes, 2009. 88p. 
MORO, C. de S.; SOUZA, G. de. Produção acadêmica brasileira sobre avaliação em Educação Infantil: primeiras aproximações. Estudos em Avaliação Educacional, São Paulo, v. 25, n. 58, p. 100-125, maio/ago. 2014.

NÓVOA, A. Professor: imagens do futuro presente. Lisboa: Educa, 2009.

RICHTER, S. R. S.; BARBOSA, M. C. S. Direitos das crianças como estratégia para pensar a educação das crianças pequenas. In: REUNIÃO ANUAL DA ASSOCIAÇÃO NACIONAL DE PÓS-GRADUAÇÃO E PESQUISA EM EDUCAÇÃO, 34, Natal, 2011. Anais eletrônicos... ANPED, 2011.

STAM, R. Mikhail Bakhtin e a crítica cultural de esquerda. In: KAPLAN, E. A. (org.). O mal-estar no pós-modernismo: teorias e práticas. Rio de Janeiro: Jorge Zahar, 1993.

SOUZA, G. de. Política e Avaliação da Educação Infantil no Brasil: tensões e desafios. RELAdEI (Revista Latinoamericana de Educación Infantil), v. 2, n. 2, p. 105-118, 2013.

VIEIRA, M. N. A.; CÔCO, V. Planejamento da avaliação institucional na educação infantil: movimentos participativos. Estud. Aval. Educ., São Paulo, v. 30, n. 74, p. 588613, maio/ago. 2019.

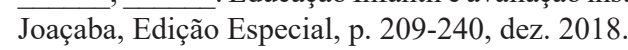

VITÓRIA. Secretaria Municipal de Educação. Gerência de Educação Infantil. A Educação Infantil do municipio de Vitória: um outro olhar. VITÓRIA, 2006.

. Secretaria Municipal de Educação. Indicadores da Qualidade na Educação Infantil Pública de Vitória. VITÓRIA, 2012.

Texto recebido em 21/06/2019.

Texto aprovado em 22/10/2019. 